\title{
APPROXIMATION OF BÖGEL CONTINUOUS FUNCTIONS AND DEFERRED WEIGHTED A-STATISTICAL CONVERGENCE BY BERNSTEIN-KANTOROVICH TYPE OPERATORS ON A TRIANGLE
}

\author{
P. N. Agrawal, Ana Maria Acu, Ruchi Chauhan and Tarul Garg
}

Abstract. The present article is in continuation of the work done by Kajla (Math. Methods Appl. Sci., 42(12), (2019), 4365-4377) on Bernstein-Kantorovich type operators on a triangle. We discuss the deferred weighted A-statistical approximation and $\tau$-th order generalization of these operators by means of a Taylor polynomial. We also investigate the convergence estimates for the functions in a Bögel space by these operators.

Mathematics subject classification (2020): 41A36, 41A25, $26 \mathrm{~A} 15$.

Keywords and phrases: Statistical convergence, generalized Boolean Sum, Bögel continuous, Bögel differentiable, mixed modulus of smoothness.

\section{REFERENCES}

[1] U. Abel, M. IVAn And R. Paltanea, The Durrmeyer variant of an operator defined by D. D. Stancu, Appl. Math. Comput., 259 (2015), 116-123.

[2] A. Altin, O. DoĞRU, F. TAşDelen, The generalization of Meyer-König and Zeller operators by generating functions, J. Math. Anal. Appl., 312 (1) (2005), 181-194.

[3] I. BADEA, Modulus of continuity in Bögel sense and some applications for approximation by a Bernstein-type operator, Studia Univ. Babes-Bolyai Ser. Math. Mech., 18 (2) (1973), 69-78 (Romanian).

[4] C. Badea, I. Badea, C. Cottin And H. H. Gonska, Notes on the degree of approximation of B-continuous and B-differentiable functions, J. Approx. Theory Appl. 4 (1988), 95-108.

[5] C. BadeA, I. BadeA AND H. H. GonskA, A test function theorem and apporoximation by pseudopolynomials, Bull. Austral. Math. Soc. 34 (1986), 53-64.

[6] B. Baxhaku, P. N. Agrawal And R. Shukla, Bivariate positive linear operators constructed by means of q-Lagrange polynomials, J. Math. Anal. Appl. 491 (2020), https://doi.org/10.1016/j.jmaa2020.124337.

[7] K. BÖGEL, Mehrdimensionale differentiation von funktionen mehrerer veränderlichen, J. Reine Angew.Math. 170 (1934), 197-217.

[8] K. BÖGEL, Über die mehrdimensionale differentiation, integration und beschränkte variation, J. Reine Angew.Math. 173 (1935), 5-29.

[9] S. Deshwal, N. Ispir And P. N. Agrawal, Blending type approximation by bivariate BernsteinKantorovich operators, Appl. Math. Inf. Sci. 11 (2) (2017), 423-432.

[10] O. DoĞRU, Approximation order and asymptotic approximation for generalized Meyer-König and Zeller operators, Math. Balkanica, 12 (3-4) (1998), 359-368.

[11] O. DoĞRU, M. A. Özarslan, F. TAşDElen, On positive operators involving a certain class of generating functions, Studia Sci. Math. Hungar., 41 (4) (2004), 415-429.

[12] H. FAST, Sur la convergence statistique, Colloq. Math. 2 (1951), 241-244.

[13] A. GAdJIEV AND C. ORHAn, Some approximation theorems via statistical convergence, Rocky Mt. J. Math. 32 (2002), 129-138. 
[14] V. Gupta, T. M. Rassias, P. N. Agrawal and A. M. Acu, Recent Advances in Constructive Approximation Theory, Springer Optim. Appl. 138, Springer, Cham, 2018, doi: 10.1007/978-3-319-92165-5.

[15] G. IçÖZ, A Kantorovich variant of a new type Bernstein-Stancu polynomials, Appl. Math. Comput., 218 (2012), 8552-8560.

[16] U. KADAK, S. A. MOHIUDDINE, Generalized statistically almost convergence based on the difference operator which includes the $(p, q)$-Gamma function and related approximation theorems, Results Math. (2018) 73:9.

[17] A. KaJla, The Kantorovich variant of operator defined by D. D. Stancu, Appl. Math. Comput. 36 (2018), 400-408.

[18] A. KaJla, Generalized Bernstein-Kantorovich-type operators on a triangle, Math. Methods Appl. Sci. 42 (12) (2019), 4365-4377.

[19] V. Karakaya AND T. A. Chishti, Weighted statistical convergence, Iran. J. Sci. Technol. Trans. A. Sci. 33 (2009), 219-223.

[20] G. Kirov AND I. Popova, A generalization of linear positive operators, Math. Balkanica. 6 (1992), $147-154$.

[21] P. P. Korovkin, Linear Operators and the Theory of Approximations, Fizmatgiz, Moscow, 1959.

[22] S. A. Mohiuddine, Approximation by bivariate generalized Bernstein Schurer operators and associated GBS operators, Adv. Difference Equ. (2020) 2020: 676.

[23] S. A. Mohiuddine, B. A. S. Alamri, Generalization of equi-statistical convergence via weighted lacunary sequence with associated Korovkin and Voronovskaya type approximation theorems, RACSAM 113, 1955-1973 (2019).

[24] S. A. Mohiuddine, Statistical weighted A-summability with application to Korovkin's type approximation theorem, J. Inequal. Appl. 2016, 101 (2016), https://doi.org/10.1186/s13660-016-1040-1.

[25] O. T. POP AND M. D. FĂRCAS, About the bivariate operators of Kantrovich type, Acta Math. Univ. Comenianae Vol. LXXVIII, 1 (2009), 43-52.

[26] S. Rahman, M. Mursaleen, A. M. Acu, Approximation properties of $\lambda$-Bernstein-Kantorovich operators with shifted knots, Math. Methods. Appl. Sci., 42 (11) (2019), 4042-4053.

[27] H. M. Srivastava, B. B. Jena, S. K. Paikray and U. K. Mishra, Deferred weighted Astatistical convergence based upon the $(p, q)$-Lagrange polynomials and its applications to approximation theorems, J. Appl. Anal. 24 (1) (2018), 1-16.

[28] D. D. STANCU, The remainder in the approximation by a generalized Bernstein operator of second order divided differences, Calcolo, 35 (1998), 53-62.

[29] F. Taşdelen, A. Olgun AND G. B. TunCA, Approximation of functions of two variables by certain linear positive operators, Proc. Indian Acad. Sci. (Math. Sci.), 117 (3) (2007), 387-399.

[30] E. V. Voronovs KaYA, Determining the asymptotic kind of the approximations of functions by $S . N$. Bernstein's polynomials, DAN SSSR A 4 (1934), 74-85.

[31] A. Zygmund, Trigonometric Series, Cambridge University Press: New York, NY, USA, 1959. 